\title{
Post-arthroscopic osteonecrosis of the medial tibial plateau: a case series
}

\author{
Axel Marx ${ }^{1 *}$ (D), Alexander Beier ${ }^{1}$, Pouria Taheri ${ }^{1}$, Martin Röpke ${ }^{2}$, Thomas Kalinski ${ }^{3}$ and Andreas M. Halder ${ }^{1}$
}

\begin{abstract}
Background: Avascular necrosis after arthroscopic surgery of the knee has already been published. The purpose of this article is to report on the frequently misdiagnosed entity of osteonecrosis of the medial tibial plateau.

Case presentation: Charts and radiographs of a consecutive series with isolated medial tibial plateau osteonecrosis were analyzed. The criterion for inclusion was the absence of trauma. Six caucasian female patients with an average age of 76.5 years complied with this criterion. Three of these cases had had arthroscopic intervention for medial meniscal lesion within the previous year.

Conclusions: The etiology of these necroses remains unclear. Osteonecrosis must be taken into account as a possible cause of persistent knee pain after surgery. Correlation between arthroscopic treatment and necrotic processes in the tibial plateau must still be regarded with skepticism.
\end{abstract}

Keywords: Osteonecrosis, Tibial plateau fracture, Arthroscopy, Osteoporosis

\section{Background}

Pain in the medial compartment of the knee is a common symptom in orthopedic practice. A number of possible causes must be considered and therefore differential diagnosis is important. If trauma can be excluded, the discomfort may be due to various degenerative conditions (Table 1).

\section{Osteonecrosis of the knee}

Spontaneous osteonecrosis (SPONK) of the medial femoral condyle was reported by Ahlback et al. in 1968 [1]. The exact etiology of this condition is still unclear, but SPONK is considered to be probably due to mechanical causes. Furthermore, correlation between meniscal tears and necrosis of the condyles is documented [2-4]. Spontaneous osteonecrosis is mainly found in the medial compartment of the knee and the defect areas are smaller than in secondary diseases $[5,6]$.

Secondary osteonecrosis (SONK) is associated with certain risk factors such as corticosteroid medications,

\footnotetext{
* Correspondence: axel@marx.eu

'Clinic for Orthopaedics, Sana Kliniken Sommerfeld, 16766 Sommerfeld, Germany

Full list of author information is available at the end of the article
}

alcohol abuse or various metabolic predisposing factors [6-13]. Various joints can be affected by SONK and bilateral defects are seen in $30-80 \%$ of cases $[5,13,14]$.

Patients diagnosed with SONK are generally slightly younger than those with SPONK (SONK: $<55$ years versus $\mathrm{SPONK}>60$ years), and women are more often affected by both conditions than men [15].

Little is known about osteonecrosis of the tibial plateau. Only $2 \%$ of osteonecrosis around the knee may affect the tibial plateau [16]. Spontaneous medial tibial plateau osteonecrosis was first described by D'Angelijan in the mid-seventies [17, 18]. It was seen to be associated with minor arthritis of the knee and also related to minimal trauma or an increased activity level [18]. The medial tibial plateau is more frequently affected than the lateral $[18,19]$, and the extent of the defects may be significantly influenced by leg axis deformity [16]. As with osteonecrosis of the femoral condyle, primary and secondary necrosis of the tibial plateau can be differentiated. Exact values for these conditions are not available in the literature.

There are no specific clinical symptoms for spontaneous and secondary osteonecrosis of the tibial plateau, but synovitis and small effusions are often found [20]. The patients report tenderness on the medial tibia, below the joint line [18]. 
Table 1 Differential diagnosis for medial compartment knee pain

Differential diagnosis
Medial meniscus lesion
Medial and/or femoropatellar osteoarthritis
Medial femur condyle osteonecrosis (M. Ahlback)
Synovitis
Intra-articular free bodies
ACL/PCL instability and medial collateral ligament lesion
Injury of the pes anserinus
Medial plica shelf syndrome
Referred pain from hip joint or lower lumbar spine disorders

$A C L$ anterior cruciate ligament, $P C L$ posterior cruciate ligament

We report on our experience with osteonecrosis of the medial tibial plateau as a rare differential diagnosis for medial knee pain. The purpose of this article is to discuss a possible correlation between surgical intervention and the natural history of this type of osteonecrosis.

\section{Case presentations}

Six caucasian cases of nontraumatic medial tibial plateau osteonecrosis with fracture of the cortical rim were treated in our department within a 12-month period. We included only cases with isolated tibial osteonecrosis in this survey. Cases with combined defects, for example, a combination with femoral condyle osteonecrosis, were excluded. Furthermore, the study included only cases with an uneventful history for trauma or ligament lesions and who had not undergone any knee or hip surgery prior to the index procedure. A standardized analysis of the biographical data, charts and operation reports was performed.

The patients underwent intensive examination for diseases and predisposition for vascular insufficiency. Clinical examination and standardized radiographs (oneleg, weight-bearing anterior-posterior and lateral, patella axial and full-leg axis) were performed in all cases. Bone quality was evaluated by dual energy X-ray absorptiometry
(DEXA) testing (GE Medical Systems, Waukesha, WI, USA). The results of these examinations are presented in Table 2.

All six patients were women and their average age was 76.5 years (70-88 years). Initial radiographs presented minimal medial osteoarthritis (stage 1 according to Kellgren and Lawrence [21], Fig. 1). One-leg axis under weight-bearing presented mild varus deformity in all the patients. There were no signs of trauma or osteonecrosis in the first radiographic assessment. None of the cases had sclerosis or osteophytes on the condyles or tibial plateau. All radiographies were analyzed by AM. The patients were initially treated by conservative methods such as physiotherapy and nonsteroidal medication for a certain period. Three patients had had arthroscopic treatment due to ongoing discomfort (case 1, 2, and 6 patient). The indication for surgery in these cases was medial meniscus lesion, and arthroscopic medial partial meniscectomy was performed (Fig. 2). There was no treatment of the tibial cartilage (for example, micro-fracturing or drilling). The early postoperative period was uneventful in all cases.

Persistent discomfort after rehabilitation led to further investigations in our department. Repeat radiographs showed isolated osteonecrosis of the medial tibial plateau with fracturing of the cortical tibial rim (case 1 patient, Fig. 3). The average interval between index surgery and identification of the medial tibial plateau osteonecrosis was 7.6 months. In all three cases (case 1, 2, and 6 patient) the medial compartment (corresponding to the partial meniscectomy) was affected.

In the three non-operated cases (case 3, 4, and 5 patient) the average interval between the occurrence of the first symptom and diagnosis of the osteonecrosis was 5 months (Table 3). The radiographies presented an identical isolated necrosis of the medial tibial plateau with a fractured cortical rim.

The radiographic staging of the defects was adapted to Carpintero [16], Lotke [18] and the modified Ficat and Arlet classification for the knee [22] (Table 4). All six cases were classified as stage 3 to 4 (Table 4).

Table 2 Clinical data of the patients

\begin{tabular}{|c|c|c|c|c|c|c|c|c|c|c|c|c|}
\hline No. & Patient & Age $(Y)$ & $\begin{array}{l}\text { Gender } \\
\text { (F/M) }\end{array}$ & Ethnicity & BMI & $\begin{array}{l}\text { DEXA } \\
t \text { value }\end{array}$ & $\mathrm{ID}$ & Medication & AS & $\begin{array}{l}\text { Interval AS } \\
\text { to ON }\end{array}$ & Radiography & $\begin{array}{l}\text { Subsequent } \\
\text { surgery }\end{array}$ \\
\hline 1 & Case 1 patient & 80 & $\mathrm{~F}$ & Caucasian & 25.6 & -2.5 & COPD & Corticosteroids & MPR & 8 months & Mild OA, ON/TP & $\overline{\text { Postponed }}$ \\
\hline 2 & Case 2 patient & 78 & $\mathrm{~F}$ & Caucasian & 22.8 & -2.6 & - & Biphosphonate & MPR, CP & 9 months & Mild OA, ON/TP & TKA \\
\hline 3 & Case 3 patient & 88 & $\mathrm{~F}$ & Caucasian & 18.1 & -4.3 & - & Biphosphonate & - & 6 months & $\begin{array}{l}\text { Mild OA, complex } \\
\text { TP \# }\end{array}$ & TKA \\
\hline 4 & Case 4 patient & 70 & $\mathrm{~F}$ & Caucasian & 30.8 & n.n. & - & - & - & - & Mild OA, ON/TP & Postponed \\
\hline 5 & Case 5 patient & 73 & $\mathrm{~F}$ & Caucasian & 20.6 & -3.2 & RA & Corticosteroids & - & - & Mild OA, ON/TP & TKA \\
\hline 6 & Case 6 patient & 70 & $\mathrm{~F}$ & Caucasian & 27.0 & -1.0 & - & - & MPR, CP & - & Mild OA, ON/TP & TKA \\
\hline
\end{tabular}

$Y$ years, $F / M$ female/male, $B M I$ body mass index, DEXA dual energy X-ray absorptiometry, ID internal diseases, COPD chronic obstructive pulmonary disease, $R A$ rheumatoid arthritis, $A S$ arthroscopic treatment, MPR meniscus partial resection, $C P$ chrondroplasty, ON osteonecrosis, OA osteoarthritis, TP tibia plateau, TP \# tibia plateau fracture, TKA total knee arthroplasty; 


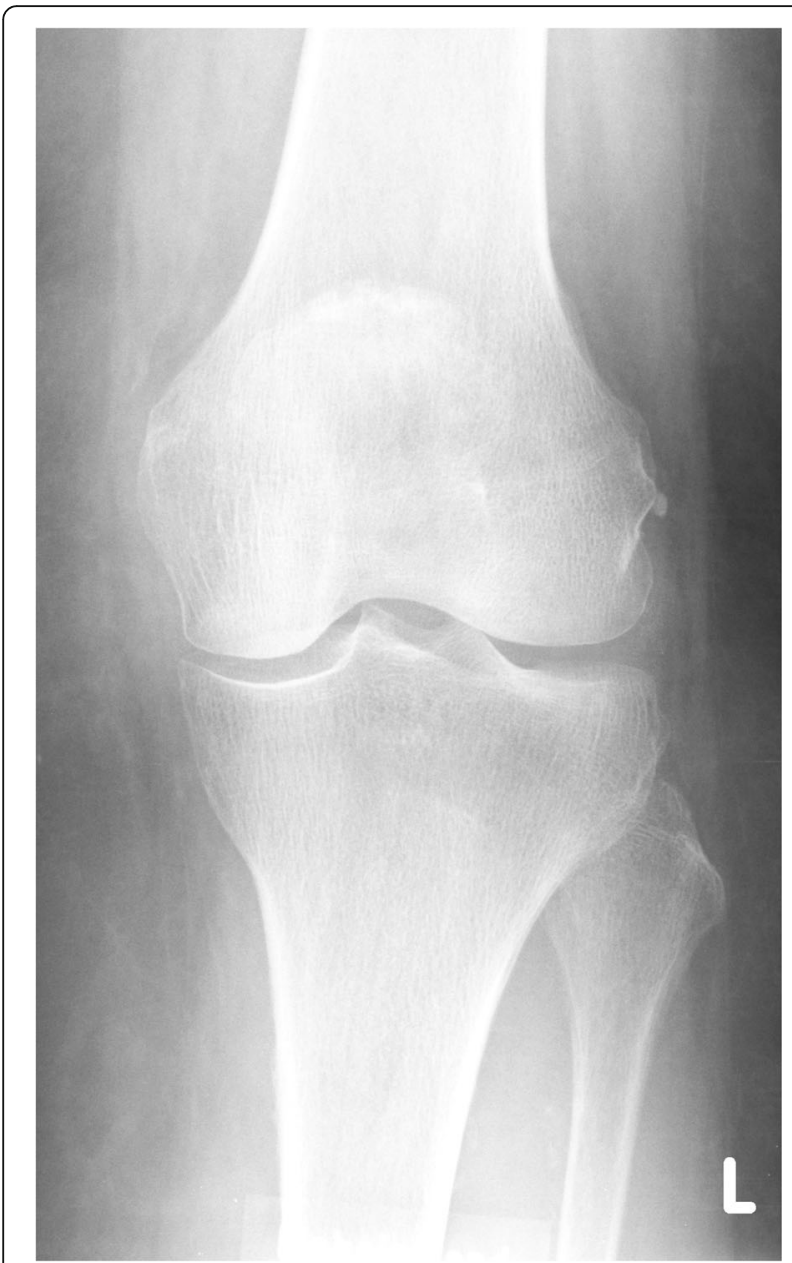

Fig. 1 Case 1 patient: anterior-posterior radiography left knee: minimal medial joint space narrowing, absence of tibial osteophytes

A magnetic resonance imaging (MRI) scan of case 1 patient is presented in Fig. 4. The preoperative MRI showed the lesion of the medial meniscus as well as concomitant slight edema of the medial tibial plateau.

A further MRI scan after arthroscopic treatment (case 1 patient) revealed the ongoing tibial process and a cystic necrotic bone defect in the medial tibial plateau (Fig. 5).

All six patients were scheduled for total knee arthroplasty. Histological analyses were performed on case 2 patient (Fig. 6) and osteonecrosis with secondary infarction of the medial plateau was detected. No infection or malignancy was seen.

\section{Discussion}

\section{Is spontaneous osteonecrosis really spontaneous?}

There are various theories regarding the genesis of these "spontaneous osteonecroses" [9]. The existence of these numerous cases of spontaneous defects of the knees has been doubted [23]. In most cases, the reasons for the ischemic bone deaths were identified and a high correlation

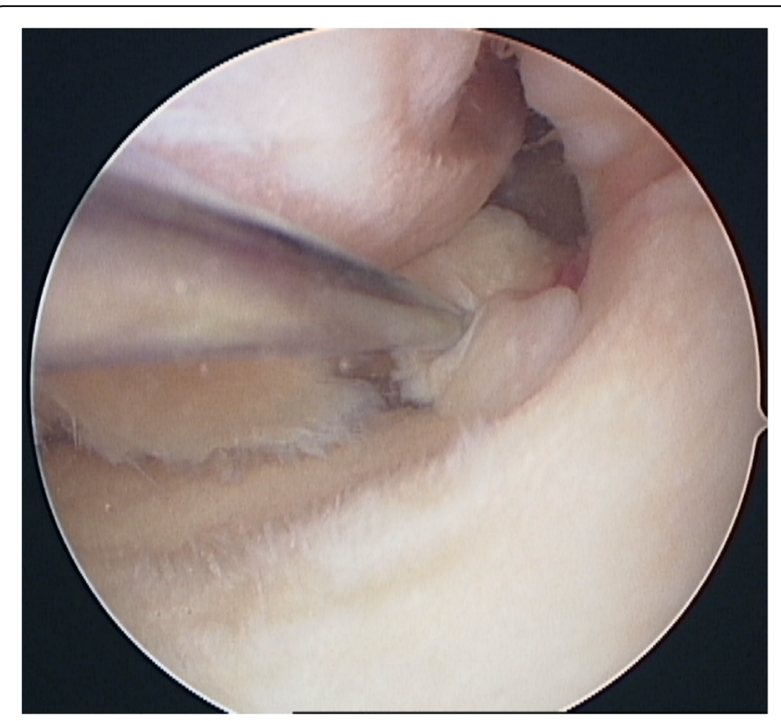

Fig. 2 Case 1 patient: arthroscopic view: posterior radial meniscal lesion due to the meniscal base, moderate cartilage lesion tibial (grade 2)

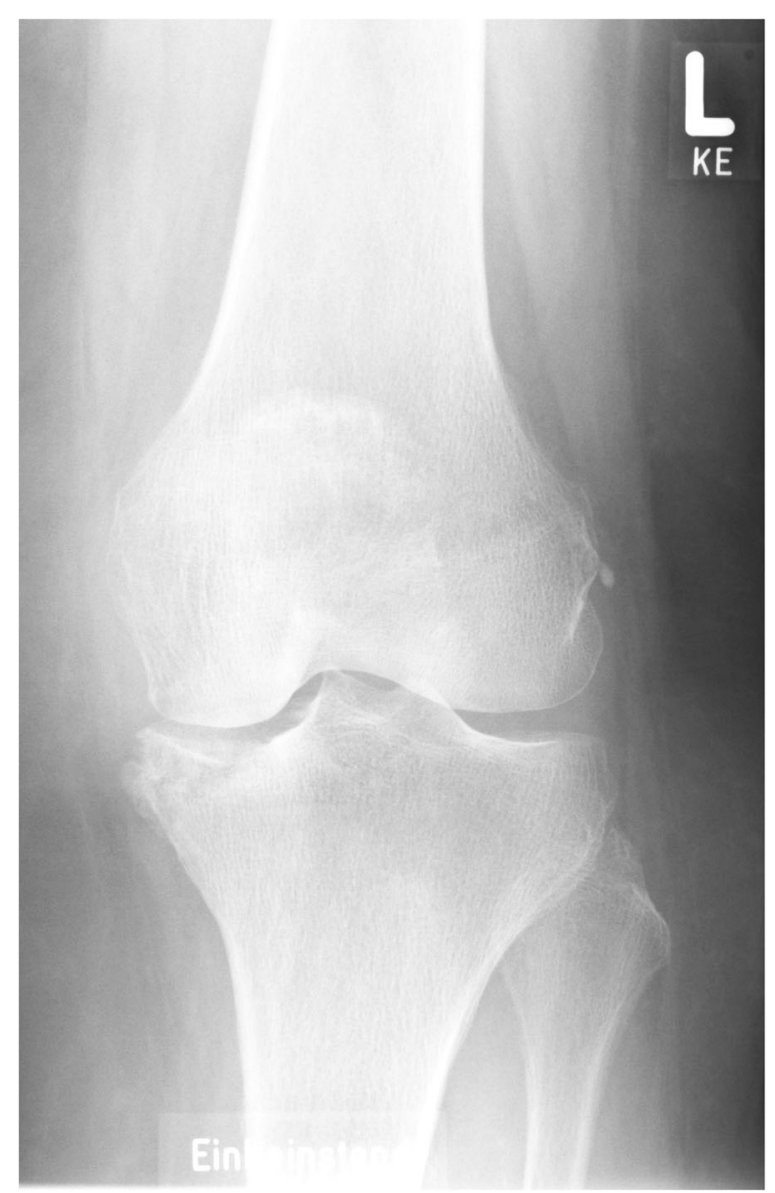

Fig. 3 Case 1 patient: anterior-posterior radiography left knee: medial tibial plateau osteonecrosis, cystic demarcation. $L=$ left, $K E$ is no information concerning the patient 
Table 3 Interval symptom to treatment

\begin{tabular}{llllll}
\hline No. & Patient & Interval symptom to AS & AS & Interval AS to ON & Interval symptom to ON \\
\hline 1 & Case 1 patient & 3 weeks & MPR & 8 months & - \\
2 & Case 2 patient & 1 year & MPR, CP & 9 months & - \\
3 & Case 3 patient & - & - & - & 2 months \\
4 & Case 4 patient & - & - & - & 9 months \\
5 & Case 5 patient & - & - & - & 4 months \\
6 & Case 6 patient & 6 months & MPR, CP & 6 months & - \\
\hline
\end{tabular}

$A S$ arthroscopic treatment, MPR meniscus partial resection, $C P$ chrondroplasty, $O N$ osteonecrosis

between meniscus tear/osteoarthritis and osteonecrosis is documented [2, 23]. Defects on the subchondral bone plate caused by chronic stress or minor trauma lead to subchondral microfracture and vascular disturbance of the bone underneath, resulting in osteonecrosis [5-9, 24, 25]. In particular, radial meniscus lesions and posterior root tears are identified as highly correlative with osteonecrosis of the femoral condyle $[9,23,26]$.

In cases of partial meniscectomy the limited buffer creates high stresses which may initiate the ischemic process $[2,3,9,10]$. On the other hand, a high incidence of meniscal lesions is documented in asymptomatic knees [27]. An MRI analysis by Navarro et al. revealed that a meniscus lesion had led to osteonecrosis on the ipsilateral side in about $57 \%$ [28].

In the recent literature the new term, "osteoporotic subchondral insufficiency/stress fracture", has been redefined $[20,23,29]$. The intention was to replace the word "spontaneous", therefore the subchondral fracture is named as a promoter of the disease. As early as the 1980s Manco et al. reported on five cases of insufficiency fractures of the tibial plateau [30]. Here, osteoporotic bone had caused fracturing of the underlying bone. Lotke et al. concluded that local stress leads to subchondral injuries and edema. Necrosis may be initiated by increasing marrow pressure [18], then repeated impact on the osteopenic or osteoarthritic bone stock leads to these microfractures. A raised activity level could also be responsible for progression of the disease. After histological analysis of fourteen cases, Yamamoto and Bullough stated that osteonecrosis was a result of a subchondral insufficiency fracture [6]. Here, the defects were located only in the femoral condyle. No isochronous meniscus lesions were specified.

\section{Treatment options}

Stage-dependent treatment is recommended. In the early stages (1 and 2), conservative treatment is still possible and may be helpful, depending on the size of the defects and the integrity of the cortical rim $[29,31]$. The use of crutches to reduce weight-bearing can help to avoid complete collapse of the compartment [31]. Additional medication with Alendron, $10 \mathrm{mg}$ per day for a month, is useful [32].

As a joint-preserving procedure, ante- or retrograde drilling can be an option to induce reperfusion of the necrotic bone area [8]. Otherwise, the results are only encouraging in the early stages (1 and 2) [22, 33]. In stages 2 and 3, high tibial osteotomies can be performed to reduce pressure on the weakened bone area [34]. Finally, implantation of a uni- or bicondylar knee replacement is the procedure which leads to the most satisfactory outcome in the treatment of persisting knee pain [20, 29, 35]. In cases of secondary osteonecrosis total knee arthroplasty seems to be more successful than hemiarthroplasty. In older patients, pre-existing osteoarthritis and defects in the cortical rim are indications for knee replacement surgery.

\section{Post-arthroscopic osteonecrosis}

During the last decade several reports have been published on "post-meniscectomy osteonecrosis" of the femoral condyle $[2-4,8,10,36-38]$. Meniscus and cartilage surgery is the common treatment in all these publications. These case series are small. Laser surgery for meniscal and

Table 4 Staging of osteonecrosis based on planar radiography, scintigraphy, and magnetic resonance imaging

\begin{tabular}{|c|c|c|c|}
\hline Stage & Radiography & Scintigraphy & Magnetic resonance imaging \\
\hline 1 & Normal & $\begin{array}{l}\text { Increased } \\
\text { uptake }\end{array}$ & $\begin{array}{l}\text { Relatively small and well localized, low signal in subchondral } \\
\text { zone (T1) }\end{array}$ \\
\hline 2 & Abnormal, cystic and sclerotic changes & $\begin{array}{l}\text { Increased } \\
\text { uptake }\end{array}$ & Low signal area subchondral zone diffused down to metaphysis \\
\hline 3 & $\begin{array}{l}\text { Crescent sign and subchondral collapse producing crescent } \\
\text { or rim sign }\end{array}$ & $\begin{array}{l}\text { Increased } \\
\text { uptake }\end{array}$ & $\begin{array}{l}\text { Changes with widespread diffusion in metaphysis, surrounded by } \\
\text { reactive bone rim, }\end{array}$ \\
\hline 4 & $\begin{array}{l}\text { Arthritic changes, joint narrowing with or without condylar } \\
\text { involvement }\end{array}$ & $\begin{array}{l}\text { Increased } \\
\text { uptake }\end{array}$ & $\begin{array}{l}\text { Diffuse areas of abnormal marrow signal intensity, involvement } \\
\text { of the condyle possible }\end{array}$ \\
\hline
\end{tabular}




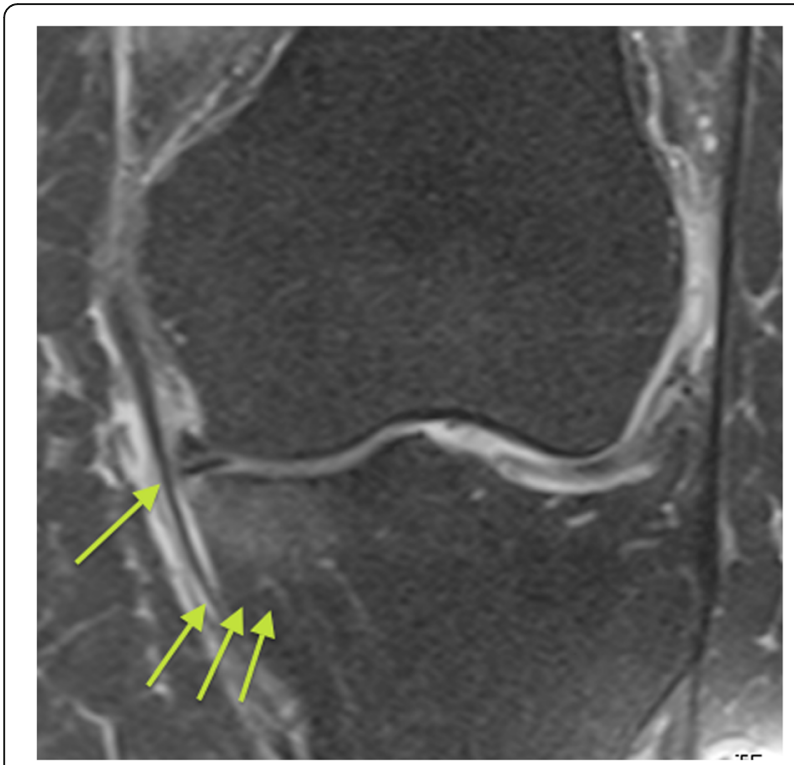

Fig. 4 Case 1 patient: preoperative T2-weighted magnetic resonance imaging left knee: slight edema of the medial tibia plateau, medial meniscus lesion. The single arrow points to the meniscus lesion, the group of three arrows point to the edema of the medial tibial plateau

chondral lesion or extensive drilling was identified as a possible cause [2, 39]. Garino et al. reported on five patients suffering from laser-induced osteonecrosis in the area of treatment [39].

Most of the published case series were retrospective and pre-existing osteonecrosis could not be excluded by preoperative diagnostics $[8,10,37]$. A four- to six-week diagnostic window to detect initial osteonecrosis is needed

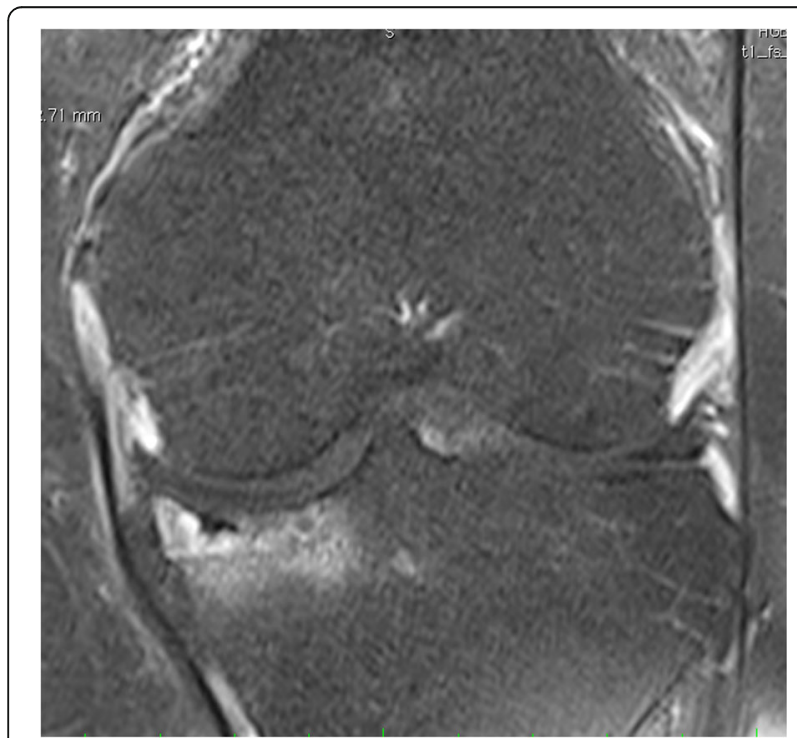

Fig. 5 Case 1 patient: postoperative T2-weighted magnetic resonance imaging left knee: progression of the tibial edema, cystic defects and depression of the medial tibia plateau

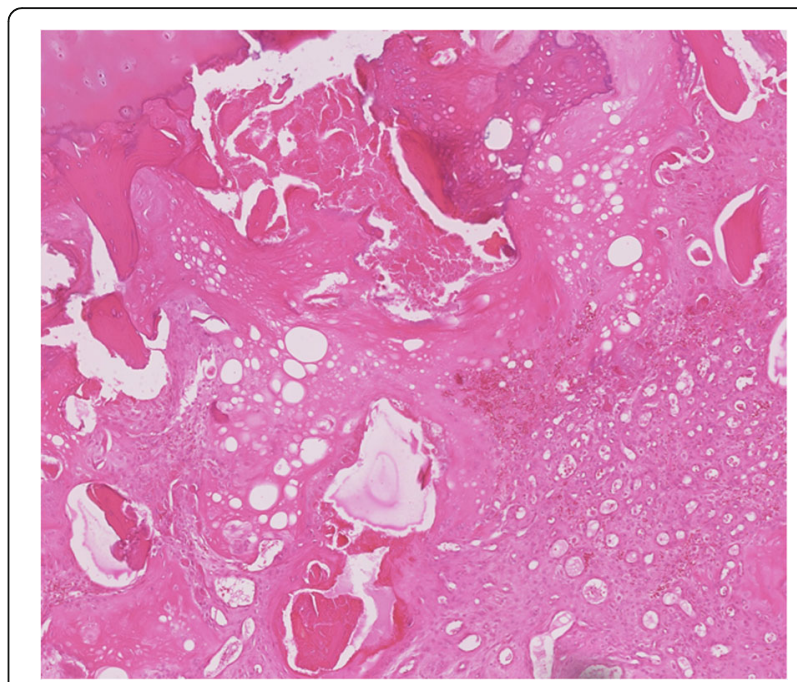

Fig. 6 Case 2 patient: histological image: osteonecrosis with secondary infraction showing necrotic debris surrounded by callus-like capillaryrich granulation tissue

[10]. In preoperative MRI this time period between the onset of pain and the MRI diagnostics should be respected in order not to miss the initial stage of the pathology [2, 10, 40]. Johnson et al. presented a case series of seven patients with post-arthroscopic osteonecrosis of the knee [2]. This is the only study with a consistent minimum period of six weeks between the onset of knee pain and the MRI diagnostics. All MRIs were documented

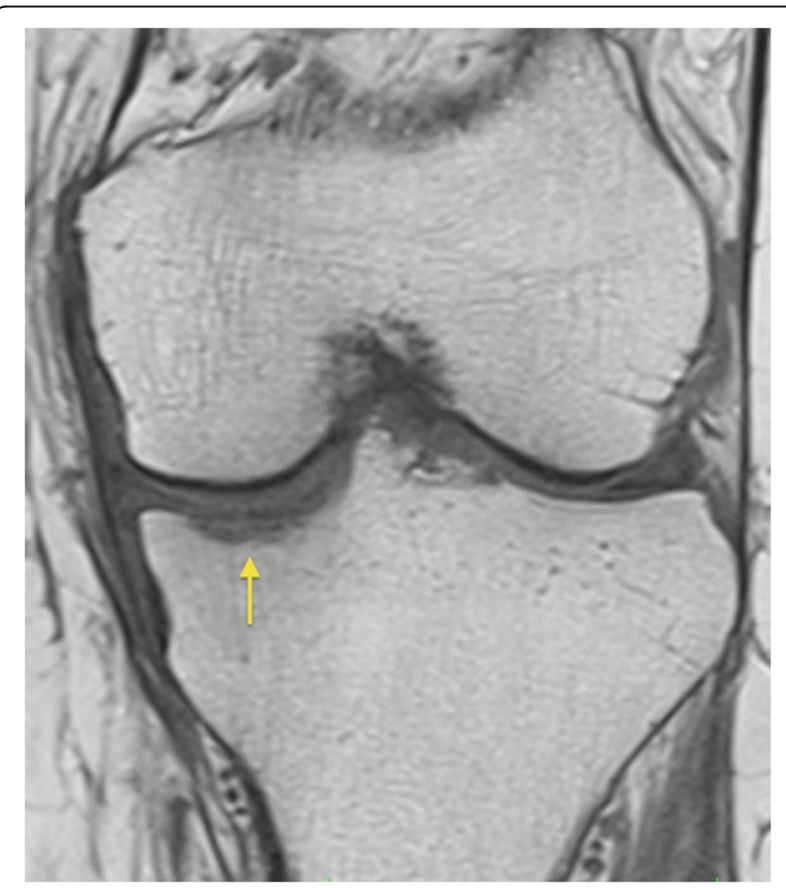

Fig. 7 Case 1 patient: preoperative T1-weighted magnetic resonance imaging left knee: underneath the articular surface linear subchondral insufficiency fracture (arrow) 
with no signs of osteonecrosis before surgical treatment. The postoperative necrosis was located in the medial condyle in four cases, in the lateral condyle in one case and in both the medial and lateral tibial plateau in the two remaining cases. The population had an average age of 60 years. A direct correlation between arthroscopy and outcome remains speculative.

Direct correlation between arthroscopic meniscus surgery and osteonecrosis of the tibial plateau cannot be proven by retrospective analysis. Inadequate surgical skill is a risk to the integrity of the femoral condyles, but plays no role in defects of the tibial plateau. It is almost impossible to cause iatrogenic damage in this area. The natural history of tibial plateau osteonecrosis may differ from that of femur condyle necrosis. In our collective, all the patients were older and female, which leads us to the opinion that gender and age are predicting factors [16]. Osteopenic bone stock is common in older female patients. DEXA analysis confirms this hypothesis in our group. In one case (case 5 patient) the periarticular osteoporosis was additionally influenced by rheumatoid arthritis.

Whether surgery had any direct influence remains unclear. Three patients with no prior surgical intervention on the knee suffered an identical tibial plateau osteonecrosis.

In the presented MRI the subchondral insufficiency fracture can already be identified preoperatively (Fig. 7). This supports the theory that osteonecrosis in the medial tibial plateau may be a physician-independent disease of the knee in older, female, and osteoporotic patients. Further investigation is necessary to prove this hypothesis.

In our management of these older female cases, preoperative MRI has been made obligatory to prevent medico-legal discussion in this population group.

\section{Conclusions}

Osteonecrosis of the tibial plateau should be considered when older osteoporotic patients complain of knee pain. Even re-assessment of primarily physiological radiographs using MRI and a new X-ray may help to identify the correct cause of the discomfort.

\footnotetext{
Abbreviations

ACL: anterior cruciate ligament; AS: arthroscopic treatment; BMI: body mass index; COPD: chronic obstructive pulmonary disease; CP: chrondroplasty; DEXA: dual energy X-ray absorptiometry; F/M: female/male; ID: internal diseases; MRI: magnetic resonance imaging; MPR: meniscus partial resection; OA: osteoarthritis; ON: osteonecrosis; PCL: posterior cruciate ligament; RA: rheumatoid arthritis; SONK: secondary osteonecrosis; SPONK: spontaneous osteonecrosis; TKA: total knee arthroplasty; TP: tibia plateau; TP \#: tibia plateau fracture; $Y$ : years
}

\section{Acknowledgements}

The authors thank Kaye Schreyer for editing and critical comments on this manuscript.

\section{Funding}

This research received no specific grant from any funding agency in the public, commercial or not-for-profit sectors.

\section{Authors' contributions}

$A M, A B$, and $A H$ participated in the whole diagnostic and treatment process of the described patients. AM and AH conceived the concept of the study. PT and MR collected the data. AM wrote the manuscript. AM, AB, PT, MR, and $\mathrm{AH}$ participated in the sequence alignment, and helped to draft the manuscript. TK performed the histological analysis. All authors read and approved the final manuscript.

\section{Competing interests}

The authors declare that they have no competing interests.

\section{Consent for publication}

All procedures followed were in accordance with the ethical standards of the responsible committee on human experimentation (institutional and national) and with the Declaration of Helsinki 1975, as revised in 2000. Written informed consent was obtained from the patients for publication of this case report and any accompanying images. A copy of the written consent is available for review by the Editor-in-Chief of this journal.

Ethics approval and consent to participate

Not applicable.

\section{Author details}

${ }^{1}$ Clinic for Orthopaedics, Sana Kliniken Sommerfeld, 16766 Sommerfeld, Germany. ${ }^{2}$ Clinic for Orthopaedics, University Magdeburg, 39120 Magdeburg, Germany. ${ }^{3}$ Department of Pathology, University Magdeburg, 39120 Magdeburg, Germany.

Received: 9 December 2015 Accepted: 12 September 2016 Published online: 19 October 2016

\section{References}

1. Ahlback S, Bauer GC, Bohne WH. Spontaneous osteonecrosis of the knee. Arthritis Rheum. 1968;11:705-33.

2. Johnson TC, Evans JA, Gilley JA, DeLee JC. Osteonecrosis of the knee after arthroscopic surgery for meniscal tears and chondral lesions. Arthroscopy. 2000;16:254-61.

3. Brahme SK, Fox JM, Ferkel RD, Friedman MJ, Flannigan BD, Resnick DL. Osteonecrosis of the knee after arthroscopic surgery: diagnosis with MR imaging. Radiology. 1991;178:851-3.

4. Pape D, Lorbach O, Anagnostakos K, Kohn D. [Osteonecrosis in the postarthroscopic knee]. Orthopade. 2008;37:1099-100. 1102-7.

5. Narvaez JA, Narvaez J, De Lama E, Sanchez A. Spontaneous osteonecrosis of the knee associated with tibial plateau and femoral condyle insufficiency stress fracture. Eur Radiol. 2003;13:1843-8.

6. Yamamoto T, Bullough PG. Spontaneous osteonecrosis of the knee: the result of subchondral insufficiency fracture. J Bone Joint Surg Am. 2000;82:858-66.

7. Myers TG, Cui Q, Kuskowski M, Mihalko WM, Saleh KJ. Outcomes of total and unicompartmental knee arthroplasty for secondary and spontaneous osteonecrosis of the knee. J Bone Joint Surg Am. 2006;88 Suppl 3:76-82.

8. Patel DV, Breazeale NM, Behr CT, Warren RF, Wickiewicz TL, O'Brien SJ. Osteonecrosis of the knee: current clinical concepts. Knee Surg Sports Traumatol Arthrosc. 1998;6:2-11.

9. Kattapuram TM, Kattapuram SV. Spontaneous osteonecrosis of the knee. Eur J Radiol. 2008;67:42-8.

10. Pape D, Seil R, Kohn D, Schneider G. Imaging of early stages of osteonecrosis of the knee. Orthop Clin North Am. 2004;35:293-303. viii.

11. Sasaki T, Yagi T, Monji J, Yasuda K, Masuda T, Fukazawa M, Konno H. Steroidinduced osteonecrosis of the femoral condyle-a clinical study of eighteen knees in ten patients. Nippon Seikeigeka Gakkai Zasshi. 1986;60:361-72.

12. Kelman GJ, Williams GW, Colwell CW Jr., Walker RH. Steroid-related osteonecrosis of the knee. Two case reports and a literature review. Clin Orthop Relat Res. 1990;257:171-6.

13. Mont MA, Baumgarten KM, Rifai A, Bluemke DA, Jones LC, Hungerford DS Atraumatic osteonecrosis of the knee. J Bone Joint Surg Am. 2000;82:1279-90. 
14. Aglietti P, Insall JN, Buzzi R, Deschamps G. Idiopathic osteonecrosis of the knee. Aetiology, prognosis and treatment. J Bone Joint Surg (Br). 1983;65:588-97.

15. Lotke PA, Ecker ML. Osteonecrosis of the knee. J Bone Joint Surg Am. 1988;70:470-3.

16. Carpintero P, Leon F, Zafra M, Montero R, Carreto A. Spontaneous collapse of the tibial plateau: radiological staging. Skeletal Radiol. 2005;34:399-404.

17. d'Angelijan G, Ryckewaert A, Glimet S. Osteonecrese du plateau tibial interna. Extr Rheumat. 1976;8:253-5.

18. Lotke PA, Nelson CL, Lonner JH. Spontaneous osteonecrosis of the knee: tibial plateaus. Orthop Clin North Am. 2004;35:365-70. x.

19. Lotke PA, Ecker ML. Osteonecrosis-like syndrome of the medial tibial plateau. Clin Orthop Relat Res. 1983;176:148-53.

20. Ecker ML, Lotke PA. Osteonecrosis of the medial part of the tibial plateau. J Bone Joint Surg Am. 1995;77:596-601.

21. Kellgren JH, Lawrence JS. Radiological assessment of osteo-arthrosis. Ann Rheum Dis. 1957;16:494-502.

22. Valenti JR, Illescas JA, Barriga A, Dolz R. Idiopathic osteonecrosis of the medial tibial plateau. Knee Surg Sports Traumatol Arthrosc. 2005;13:293-8.

23. Kidwai AS, Hemphill SD, Griffiths HJ. Radiologic case study. Spontaneous osteonecrosis of the knee reclassified as insufficiency fracture. Orthopedics. 2005;28(236):333-6.

24. Satku K, Kumar VP, Chacha PB. Stress fractures around the knee in elderly patients. A cause of acute pain in the knee. J Bone Joint Surg Am. 1990;72:918-22.

25. Satku K, Kumar VP, Chong SM, Thambyah A. The natural history of spontaneous osteonecrosis of the medial tibial plateau. J Bone Joint Surg (Br). 2003;85:983-8

26. Yao L, Stanczak J, Boutin RD. Presumptive subarticular stress reactions of the knee: MRI detection and association with meniscal tear patterns. Skeletal Radiol. 2004;33:260-4.

27. Noble J, Hamblen DL. The pathology of the degenerate meniscus lesion. J Bone Joint Surg (Br). 1975;57:180-6.

28. Cegarra Navarro MF, Martinez Fernandez M, Blanco Barrio A, Lloret EF. Can MRI determine whether acute or chronic processes predisposing conditions are present in spontaneous osteonecrosis of the knee? Radiologia. 2010:52:234-40.

29. Kim JY, Finger DR. Spontaneous osteonecrosis of the knee. J Rheumatol. 2006;33:1416.

30. Manco LG, Schneider R, Pavlov H. Insufficiency fractures of the tibial plateau. AJR Am J Roentgenol. 1983;140:1211-5.

31. Marmor L. Fracture as a complication of osteonecrosis of the tibial plateau. A case report. J Bone Joint Surg Am. 1988;70:454-7.

32. Cabitza P, Tamim H. Occult fractures of tibial plateau detected employing magnetic resonance imaging. Arch Orthop Trauma Surg. 2000;120:355-7.

33. Rozing PM, Insall J, Bohne WH. Spontaneous osteonecrosis of the knee. J Bone Joint Surg Am. 1980;62:2-7.

34. Koshino T. The treatment of spontaneous osteonecrosis of the knee by high tibial osteotomy with and without bone-grafting or drilling of the lesion. J Bone Joint Surg Am. 1982;64:47-58.

35. Bruni D, lacono F, Raspugli G, Zaffagnini S, Marcacci M. Is unicompartmental arthroplasty an acceptable option for spontaneous osteonecrosis of the knee? Clin Orthop Relat Res. 2012;470:1442-51.

36. Muscolo DL, Costa-Paz M, Makino A, Ayerza MA. Osteonecrosis of the knee following arthroscopic meniscectomy in patients over 50-years old. Arthroscopy. 1996;12:273-9.

37. Faletti C, Robba T, de Petro P. Postmeniscectomy osteonecrosis. Arthroscopy. 2002;18:91-4

38. Prues-Latour V, Bonvin JC, Fritschy D. Nine cases of osteonecrosis in elderly patients following arthroscopic meniscectomy. Knee Surg Sports Traumatol Arthrosc. 1998:6:142-7.

39. Garino JP, Lotke PA, Sapega AA, Reilly PJ, Esterhai Jr JL. Osteonecrosis of the knee following laser-assisted arthroscopic surgery: a report of six cases. Arthroscopy. 1995;11:467-74.

40. Nakamura T, Matsumoto T, Nishino M, Tomita K, Kadoya M. Early magnetic resonance imaging and histologic findings in a model of femoral head necrosis. Clin Orthop Relat Res. 1997:334:68-72.

\section{Submit your next manuscript to BioMed Central and we will help you at every step:}

- We accept pre-submission inquiries

- Our selector tool helps you to find the most relevant journal

- We provide round the clock customer support

- Convenient online submission

- Thorough peer review

- Inclusion in PubMed and all major indexing services

- Maximum visibility for your research

Submit your manuscript at www.biomedcentral.com/submit

) Biomed Central 